\title{
Expression of cyclin E in stage III colorectal carcinoma
}

\author{
LEA RATH-WOLFSON ${ }^{1,4}$, MICHAEL BERGMAN ${ }^{2,4}$, YAACOV ORI ${ }^{2,4}$, ALEX GOLDMAN ${ }^{2,4}$, \\ EDWARD RAM $^{3,4}$, RUMELIA KOREN ${ }^{1,4}$ and HERTZEL SALMAN ${ }^{2,4}$ \\ Departments of ${ }^{1}$ Pathology, ${ }^{2}$ Internal Medicine 'C' and ${ }^{3}$ Surgery 'A', Hasharon Hospital, Rabin Medical \\ Center, Petah-Tiqva; ${ }^{4}$ Sackler School of Medicine, Tel-Aviv University, Ramat-Aviv, Israel
}

Received June 10, 2012; Accepted September 25, 2012

DOI: $10.3892 / \mathrm{ol} .2012 .955$

\begin{abstract}
Carcinogenesis is characterized by an abnormal regulation of the cell cycle. Regulators of the cell cycle such as cyclin E play an important role in neoplasia and may be correlated with prognosis. The clinical significance of the expression of cyclin $\mathrm{E}$ in stage III colorectal carcinoma has not yet been investigated. The expression of cyclin E was evaluated in 49 patients. Using a multivariate analysis, the expression of cyclin $\mathrm{E}$ in the tumor at diagnosis was compared with various clinicopathological variables, including age, gender, tumor site, tumor size, tumor differentiation and lymph node involvement. There were more node-positive cases in the cyclin E-negative group than in the cyclin E-positive group $(\mathrm{P}=0.003)$. However, there was no correlation between the degree of cyclin E expression and the clinical data. In conclusion, our data suggest that overexpression of cyclin E does not predict the clinical outcome in colorectal cancer stage III. Negative cyclin E staining may be associated with lymph node involvement.
\end{abstract}

\section{Introduction}

Colorectal cancer (CRC) is the third most commonly diagnosed cancer in males and females. In 2011, 141,210 new cases were diagnosed and 49,380 mortalities from CRC occurred (1). Colorectal cancerogenesis is a result of complicated molecular mechanisms and disturbances of the cell cycle and requires a number of genetic alterations (2-4). One of the main characteristics of malignant tumors is abnormal regulation of cell growth. Cell cycle abnormality is the leading factor in tumor progression. Cyclins are a family of proteins that control the progression of cells through the cell cycle by activating cyclin-dependent kinase (CDK) enzymes $(5,6)$. Cyclin E, through binding and activation of CDK2, facilitates cell transition from $\mathrm{G} 1$ to $\mathrm{S}$ phase. Conversely, impaired

Correspondence to: Dr Hertzel Salman, Department of Internal Medicine 'C', Rabin Medical Center, Hasharon Hospital, 7 KKL Street, Petah-Tiqva 49372, Israel

E-mail: dc375380@netvision.net.il

Key words: cyclin E, colorectal carcinoma, cell cycle, prognostic factors activity of the cyclin E/CDK2 complex arrests the cell before new DNA is synthesized. The precisely timed degradation of cyclins is one of the mechanisms that regulate CDK activity, which is necessary for coordination of the cell cycle and may prevent the development of cancer cells $(7,8)$. Cyclin E overexpression increases cell proliferation via enforced progression to $\mathrm{S}$ phase and may lead to carcinogenesis (9). The cyclin $\mathrm{E}$ gene is overexpressed, and protein concentrations and related kinase activity are often altered, in numerous human tumors. Impaired expression of cyclin $\mathrm{E}$ has been identified in breast, ovarian, gastric, colorectal and non-small lung cancers, leukemias, lymphomas and melanomas (7,10-17).

An additional significant finding is the overexpression of cyclin E mRNA in three CRC cell lines (LoVo, $\mathrm{CaCo} 2$ and HT29) with an aberrant number of chromosomes (18). Simone et al proposed that overexpressed cyclin E mRNA may maintain the abnormal chromosome number and support cells with high indices of proliferation and altered genotypes (18). The activation of cyclin $\mathrm{E}$ in neoplasia may involve mutations in regulatory pathways, supporting abnormal proliferation and the development of cancer. During the last decade, efforts have been made to discover new predictive and prognostic markers in gastrointestinal and CRCs (19).

The role of cyclin $\mathrm{E}$ as a prognostic marker in colorectal carcinoma is controversial. The purpose of our study was to evaluate cyclin E expression in patients with stage III colorectal carcinoma.

\section{Materials and methods}

Clinicopathological data. The study was approved by the IRB of the Rabin Medical Center. The study included 49 patients with metastatic CRC (29 males and 20 females; mean age, 66.2 years; range, 50-81 years). All patients underwent surgical resection of the tumor at the Rabin Medical Center between 1996 and 2005. Patients with stage III cancers according to the AJCC (American Joint Committee on Cancer) $(20,21)$ classification were selected. All patients had metastatic disease, either at diagnosis or during the course of their disease. The median follow-up was 71 months. All patients received the same standard first-line treatment for metastatic CRC and the response to this treatment was determined. The first-line treatment in all cases was a standard combination of 5-FU, leucovorin (LV) and irinotecan (FOLFIRI regimen). Tumor samples from these patients were examined. Each sample 
contained an area of adenocarcinoma with some adjacent normal colonic mucosa.

Immunohistochemistry. Cyclin E protein expression was evaluated by immunohistochemistry using a monoclonal antibody clone (Abcam, Cambridge, UK) that recognizes an intracellular domain of the cyclin E protein. Tissue sections (4 $\mu \mathrm{m}$ thick) were cut, deparaffinized in xylene, rehydrated with graded ethanol and immersed in hydrogen peroxide for $20 \mathrm{~min}$. The slides were heated in a microwave oven at $300 \mathrm{~W}$ and left in the Coplin jar at room temperature for $30 \mathrm{~min}$. To block non-specific binding of the primary antibody, a normal goat serum was used for $15 \mathrm{~min}$. After removing the blocking solution, the primary antibody for cyclin E (Abcam) was applied at a dilution of 1:200 for $15 \mathrm{~min}$ in a modified chamber at room temperature. Negative control studies were performed without applying the primary antibody. The sections were washed with PBS, incubated with polymer detection kit (HRP broad spectrum; Zymed, Carlsbad, CA, USA) for $15 \mathrm{~min}$ at room temperature, then rinsed with washing buffer and incubated with diaminobenzidine tetrahydrochloride (DAB) at room temperature for $5 \mathrm{~min}$ and rinsed with running water for 3 min. Counter staining was carried out with Mayer's hematoxylin for $5 \mathrm{~min}$, dehydrated in a series of ethanol and mounted with glass cover slips using Permount. In each case, the entire section was systemically examined for cyclin E immunoreactivity.

The cyclin E labeling index was defined as the percentage of tumor cells exhibiting nuclear immunoreactivity and was calculated by counting cyclin E nuclear stained tumor cells in 1,000 tumor cells. A single representative section from each sample was surveyed microscopically at x100 for at least two areas of the highest cyclin E intensity of positive cells. Cell counts were carried out at $\mathrm{x} 400$ in at least five fields in these areas. Tumor samples were judged to be negative $(<2 \%)$ or positive $(>2 \%)$ according to the percentage of the cells showing the nuclear stain pattern (22). A positive control slide was stained with each series.

Statistical analysis. Univariate and multivariate analysis were used to determine the correlation between clinicopathological variables and the cyclin E staining positivity. The Chi-square test was used to evaluate the correlation between the node status and cyclin E positivity. $\mathrm{P}<0.05$ was considered statistically significant.

\section{Results}

The specimens were obtained from 29 male and 20 female patients. A total of 37 tumors (75.5\%) were in the colon while 12 $(24.5 \%)$ were located in the rectum. All tumors were stage III. N0 was observed in 14, N1 in 19 and N2 in 16 patients. The mean follow-up time was 71 months (range, 22-91).

We identified positive cyclin E staining in the tumor tissue. In 28 patients the tumors had no cyclin E expression, while the remaining 21 cases had various degrees of cyclin E positivity, from 3 to $50 \%$. The positive staining was observed in the nuclei of the malignant epithelial cells. There was also a positive nuclear stain in the nuclei of small lymphocytes in the stroma of the tumors, which were ignored in the count.
Table I. Correlation between cyclin E and node status.

\begin{tabular}{lcccc}
\hline Cyclin E & $\begin{array}{c}\text { Node- } \\
\text { negative (\%) }\end{array}$ & $\begin{array}{c}\text { Node- } \\
\text { positive (\%) }\end{array}$ & $\begin{array}{c}\text { Total } \\
\text { number }\end{array}$ & P-value \\
\hline Negative & $3(10.7)$ & $25(89.3)$ & 28 & 0.003 \\
Positive & $11(52.4)$ & $10(47.6)$ & 21 & \\
\hline
\end{tabular}

Results were obtained using a Chi-square test.

A

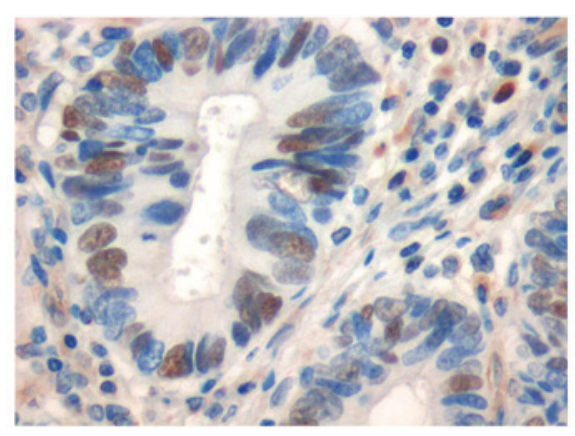

B

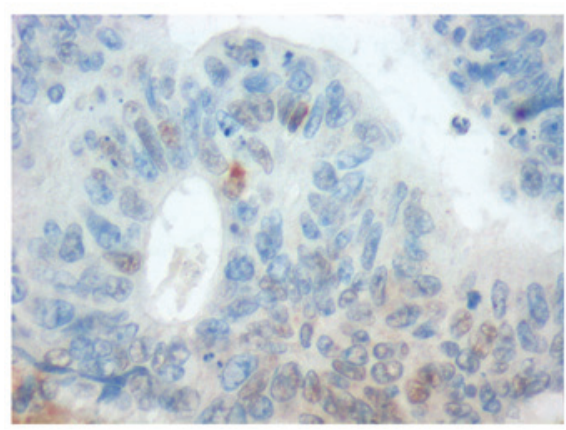

C

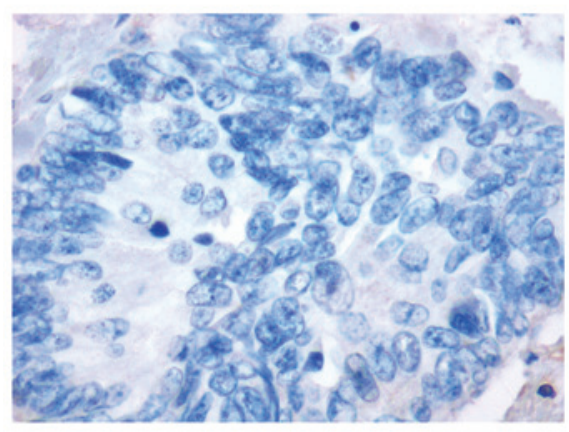

Figure 1. Cyclin E-positive stain in (A) $30 \%$ and (B) $3 \%$ of tumor nuclei. (C) Cyclin E-negative stain in the tumor nuclei. Magnification, $\mathrm{x} 40$.

The degree of cyclin E expression varied in the tumor tissue of the different patients as shown in (Fig. 1).

There was no correlation between the degree of cyclin $\mathrm{E}$ expression and the clinical data. A statistically significant correlation was identified when the $\mathrm{N}$-stage was compared with cyclin E expression ( $\mathrm{P}=0.003$; Table I).

\section{Discussion}

The degree of invasion and nodal status are the main prognostic indicators of the outcome in CRC. In the TN staging 
category, the prognosis of stages I and IV is predictable while the outcomes of stages II and III have a broad spectrum. The 5-year survival rate in stage III CRC is approximately $75 \%$ (21). There is a need for the identification of new prognostic biomarkers which may be implemented in clinical practice for the identification of patients with stage III CRC who have higher survival potential (19). The detection of such markers may aid in risk stratification and cyclin E may be included in the list of possible candidates.

The role of cyclin E in colon tumorgenesis is supported by certain studies which revealed overexpression of cyclin E in early stages of tumor development $(17,23)$. Positive cyclin E staining was correlated with $\mathrm{Ki}-67$ antigen (a marker of proliferative activity of malignant cells) and p53 protein level in these cells $(3,24)$. This finding supports the contribution of cyclin $\mathrm{E}$ to abnormal regulation of the cell cycle, affecting colorectal carcinogenesis (7). Yasui et al found expression of cyclin $\mathrm{E}$ in $25 \%$ of human colorectal adenomas and $56 \%$ of adenocarcinomas (15). Increased levels of cyclin $E$ in certain cases indicate gene amplification $(25,26)$. Corin et al revealed a significant correlation between high total cyclin $\mathrm{E}$ expression and cancer-specific survival in patients with colon cancer (17). Zhou et al found that cyclin E overexpression is a strong negative predictor for survival in patients with rectal cancer (27). The results of the study by Kitahara et al support the possibility that cyclin E gene amplification may play a role in the pathogenesis of CRC (26). Iwatsuki et al studied FBXW7, a cell cycle regulating gene involved in cyclin E degradation, and found that in the case of low FBXW7 protein expression there was strong cyclin E protein expression in CRC (28).

The current knowledge regarding the role of cyclin $\mathrm{E}$ as a prognostic marker in CRC is controversial. In a group of patients younger than 45 years old with early-onset CRC, a lack of cyclin E expression was correlated with higher mortality (29).

Cyclin E was absent in $86 \%$ of microsatellite-stable CRCs in a younger group (29). Sutter et al revealed that cyclin E was overexpressed in colorectal tumors with high microsatellite instability, and suggested that increased expression of cyclin E may contribute to the mutator phenotype of CRC (30). Cells from colorectal cell lines with an aberrant number of chromosomes had a higher cyclin E mRNA expression. This finding supports the role of cyclin $\mathrm{E}$ as a factor involved in the chromosome instability phenotype in vitro (18). However, certain studies revealed that cyclin E overexpression was correlated with certain clinicopathological features, but could not be used as a prognostic marker of early recurrence and survival (23). Lim et al revealed that cyclin E expression did not predict poor prognosis in patients with stage II colorectal carcinomas (31). Li et al demonstrated that the three-year survival rate of a cyclin E-negative group was significantly lower than that of the cyclin E-positive group (32). The findings of Wang et al support the theory of overexpression of cyclin E in CRC without a significant correlation with clinical and pathological characteristics (33). Bondi et al did not identify a significant correlation between cyclin E expression and gene amplification in primary colon adenocarcinomas and clinical outcome (34). Cyclin E was found to be higher in rectal cancer compared with colon cancer in a study from Norway (35). In light of the above, the possible role of the expression of cyclin $\mathrm{E}$ as a prognostic marker in CRC is unclear. Cyclin E overexpression was observed in certain studies, while negative cyclin $\mathrm{E}$ staining was revealed in others. Thus, there are insufficient data to apply cyclin E for clinical and prognostic purposes in CRC. In the present study, in patients with T3 CRC, there were more lymph node-positive cases in the cyclin E-negative group than in the cyclin E-positive group $(\mathrm{P}=0.003)$ when we compared the node status with the cyclin E expression. Our data support the findings of Li et al (32). In their study of 304 patients with colorectal tumors, low levels of cyclin E were significantly correlated with neoplasm size, deep invasion, multiple metastases and poor prognosis (32). According to their interpretation of the data, tumor progression is associated with loss of cyclin E expression. We did not identify a significant correlation between the degree of cyclin E expression and the clinical data in our patients with T3 CRC.

Thus, the role of cyclin $\mathrm{E}$ as a prognostic marker in gastrointestinal cancer requires further study, with focus on the lymph node status and cyclin E expression.

\section{References}

1. American Cancer Society: Cancer Facts and Figures 2011. Atlanta, GA: American Cancer Society, 2011. www.cancer.org/ Research/CancerFactsFigures/index. Accessed, July 272011.

2. Tortolina L, Castagnino N, De Ambrosi C, Moran E, Patrone F, Ballestrero A and Parodi S: A multi-scale approach to colorectal cancer: from a biochemical-interaction signaling-network level, to multi-cellular dynamics of malignant transformation. Interplay with mutations and onco-protein inhibitor drugs. Curr Cancer Drug Targets 12: 339-355, 2012.

3. Minoo P, Zlobec I, Peterson M, Terracciano L and Lugli A: Characterization of rectal, proximal and distal colon cancers based on clinicopathological, molecular and protein profiles. Int J Oncol 37: 707-718, 2010.

4. Kanwar SS, Poolla A and Majumdar AP: Regulation of colon cancer recurrence and development of therapeutic strategies. World J Gastrointest Pathophysiol 3: 1-9, 2012.

5. Siu KT, Rosner MR and Minella AC: An integrated view of cyclin E function and regulation. Cell Cycle 11: 57-64, 2012.

6. Koff A, Cross F, Fisher A, Schumacher J, Leguellec K, Philippe M and Roberts JM: Human cyclin E, a new cyclin that interacts with two members of the CDC2 gene family. Cell 66: 1217-1228, 1991.

7. Stamatakos M, Palla V, Karaiskos I, Xiromeritis K, Alexiou I, Pateras I and Kontzoglou K: Cell cyclins: triggering elements of cancer or not? World J Surg Oncol 8: 111, 2010.

8. MacLachlan TK, Sang N and Giordano A: Cyclins, cyclindependent kinases and cdk inhibitors: implications in cell cycle control and cancer. Crit Rev Eukaryot Gene Expr 5: 127-156, 1995.

9. Howard CM, Claudio PP, De Luca A, et al: Inducible pRb2/p130 expression and growth-suppressive mechanisms: evidence of a $\mathrm{pRb} 2 / \mathrm{p} 130$, p27Kip1, and cyclin E negative feedback regulatory loop. Cancer Res 60: 2737-2744, 2000.

10. Salon C, Merdzhanova G, Brambilla C, Brambilla E, Gazzeri S and Eymin B: E2F-1, Skp2 and cyclin E oncoproteins are upregulated and directly correlated in high-grade neuroendocrine lung tumors. Oncogene 26: 6927-6936, 2007.

11. Shaye A, Sahin A, Hao Q, Hunt K, Keyomarsi K and Bedrosian I: Cyclin E deregulation is an early event in the development of breast cancer. Breast Cancer Res Treat 115: 651-659, 2009.

12. Keyomarsi K, Tucker SL, Buchholz TA, et al: Cyclin E and survival in patients with breast cancer. N Engl J Med 347: 1566-1575, 2002.

13. Bedrosian I, Lu KH, Verschraegen $\mathrm{C}$ and Keyomarsi K: Cyclin E deregulation alters the biologic properties of ovarian cancer cells. Oncogene 23: 2648-2657, 2004.

14. Tenderenda M: A study on the prognostic value of cyclins D1 and $\mathrm{E}$ expression levels in resectable gastric cancer and on some correlations between cyclins expression, histoclinical parameters and selected protein products of cell-cycle regulatory genes. J Exp Clin Cancer Res 24: 405-414, 2005. 
15. Yasui W, Kuniyasu H, Yokozaki H, Semba S, Shimamoto F and Tahara E: Expression of cyclin E in colorectal adenomas and adenocarcinomas: correlation with expression of Ki-67 antigen and p53 protein. Virchows Arch 429: 13-19, 1996.

16. Griniatsos J, Michail OP, Theocharis S, et al: Circadian variation in expression of G1 phase cyclins D1 and E and cyclin-dependent kinase inhibitors p16 and p21 in human bowel mucosa. World J Gastroenterol 12: 2109-2114, 2006.

17. Corin I, Larsson L, Bergström J, Gustavsson B and Derwinger K: A study of the expression of Cyclin $\mathrm{E}$ and its isoforms in tumor and adjacent mucosa, correlated to patient outcome in early colon cancer. Acta Oncol 49: 63-69, 2010.

18. Simone C, Resta N, Bagella L, Giordano A and Guanti G: Cyclin $\mathrm{E}$ and chromosome instability in colorectal cancer cell lines. Mol Pathol 55: 200-203, 2002.

19. Zeestraten EC, Maak M, Shibayama M, et al: Specific activity of cyclin-dependent kinase I is a new potential predictor of tumour recurrence in stage II colon cancer. Br J Cancer 106: 133-140, 2012.

20. Steinberg SM, Barkin JS, Kaplan RS and Stablein DM: Prognostic indicators of colon tumors. The Gastrointestinal Tumor Study Group experience. Cancer 57: 1866-1870, 1986.

21. Gunderson LL, Jessup JM, Sargent DJ, Greene FL and Stewart AK: Revised TN categorization for colon cancer based on national survival outcomes data. J Clin Oncol 28: 264-271, 2010.

22. Potemski P, Kusinska R, Watala C, Pluciennik E, Bednarek AK and Kordek R: Prognostic relevance of basal cytokeratin expression in operable breast cancer. Oncology 69: 478-485, 2005.

23. Ioachim E: Expression patterns of cyclins D1, E and cyclindependent kinase inhibitors p21waf1/cip1, p27kip1 in colorectal carcinoma: correlation with other cell cycle regulators ( $\mathrm{pRb}, \mathrm{p} 53$ and Ki-67 and PCNA) and clinicopathological features. Int J Clin Pract 62: 1736-1743, 2008.

24. Li JQ, Wu F, Masaki T, et al: Correlation of Skp2 with carcinogenesis, invasion, metastasis, and prognosis in colorectal tumors. Int J Oncol 25: 87-95, 2004.

25. Donnellan R and Chetty R: Cyclin E in human cancers. FASEB J 13: 773-780, 1999.
26. Kitahara K, Yasui W, Kuniyasu H, et al: Concurrent amplification of cyclin $\mathrm{E}$ and $\mathrm{CDK} 2$ genes in colorectal carcinomas. Int J Cancer 62: 25-28, 1995.

27. Zhou YJ, Xie YT, Gu J, Yan L, Guan GX and Liu X: Overexpression of cyclin $\mathrm{E}$ isoforms correlates with poor prognosis in rectal cancer. Eur J Surg Oncol 37: 1078-1084, 2011.

28. Iwatsuki M, Mimori K, Ishii H, et al: Loss of FBXW7, a cell cycle regulating gene, in colorectal cancer: clinical significance. Int J Cancer 126: 1828-1837, 2010.

29. Perea J, Alvaro E, Rodríguez Y, et al: Approach to early-onset colorectal cancer: clinicopathological, familial, molecular and immunohistochemical characteristics. World J Gastroenterol 16: 3697-3703, 2010

30. Sutter T, Dansranjavin T, Lubinski J, Debniak T, Giannakudis J, Hoang-Vu C and Dralle $\mathrm{H}$ : Overexpression of cyclin $\mathrm{E}$ protein is closely related to the mutator phenotype of colorectal carcinoma. Int J Colorectal Dis 17: 374-380, 2002.

31. Lim YJ, Kim YH, Ahn GH, et al: Cyclin E, p27 and mutant p53 do not predict the prognosis in AJCC stage II colorectal carcinomas. Korean J Gastroenterol 44: 314-320, 2004.

32. Li JQ, Miki H, Ohmori M, Wu F and Funamoto Y: Expression of cyclin $\mathrm{E}$ and cyclin-dependent kinase 2 correlates with metastasis and prognosis in colorectal carcinoma. Hum Pathol 32: 945-953, 2001.

33. Wang A, Yoshimi N, Suzui M, Yamauchi A, Tarao M and Mori H: Different expression patterns of cyclins A, D1 and E in human colorectal cancer. J Cancer Res Clin Oncol 122: 122-126, 1996.

34. Bondi J, Husdal A, Bukholm G, Nesland JM, Bakka A and Bukholm IR: Expression and gene amplification of primary (A, $\mathrm{B} 1, \mathrm{D} 1, \mathrm{D} 3$, and $\mathrm{E})$ and secondary $(\mathrm{C}$ and $\mathrm{H})$ cyclins in colon adenocarcinomas and correlation with patient outcome. J Clin Pathol 58: 509-514, 2005.

35. Aamodt R, Jonsdottir K, Andersen SN, Bondi J, Bukholm G and Bukholm IR: Differences in protein expression and gene amplification of cyclins between colon and rectal adenocarcinomas. Gastroenterol Res Pract 2009: 285830, 2009. 